Article

\title{
Evaluation of D-Limonene and $\beta$-Ocimene as Attractants of Aphytis melinus (Hymenoptera: Aphelinidae), a Parasitoid of Aonidiella aurantii (Hemiptera: Diaspididae) on Citrus spp.
}

\author{
Khalid Mohammed ${ }^{1,2,+}\left(\mathbb{D}\right.$, Manjree Agarwal ${ }^{1,+}+{ }^{+}$, Beibei Li $^{3}$, James Newman ${ }^{1}$, Tao Liu ${ }^{4, *}$ and \\ Yonglin Ren $1, *$ (D) \\ 1 College of Science, Health, Engineering and Education, Murdoch University, Perth, Western Australia 6150, \\ Australia; k.mohammed@murdoch.edu.au (K.M.); m.agarwal@murdoch.edu.au (M.A.); \\ james.newman@cbh.com.au (J.N.) \\ 2 College of Agriculture and Forestry, University of Mosul, Mosul 41002, Iraq \\ 3 College of agriculture, Kansas State University, Manhattan, KS 66502, USA; libeibei@ksu.edu \\ 4 Institute of Equipment Technology, Chinese Academy of Inspection and Quarantine, Beijing 100123, China \\ * Correspondence: liutao_caiq@163.com (T.L.); y.ren@murdoch.edu.au (Y.R.); Tel.: +61-40-975-8976 (Y.R.) \\ + Authors contributed to this work equally.
}

Received: 22 November 2019; Accepted: 6 January 2020; Published: 8 January 2020

check for updates

\begin{abstract}
The volatile organic compounds (VOCs) released from herbivore-infested plants can be used as chemical signals by parasitoids during host location. In this research, we investigated the VOC chemical signals for the parasitoid Aphytis melinus to discriminate between Aonidiella aurantii (California red scale)-infested fruit and non-infested fruit on three different citrus species. First, we identified the chemical stimuli emanating from non-infested and A. aurantii-infested citrus fruits via solid phase microextraction (SPME) and gas chromatography-mass spectrometry (GC-MS) analyses and identified 34 volatile organic compounds (VOCs). The GC-MS analysis showed qualitative and quantitative differences between VOCs emitted from non-infested and infested citrus fruit. Two VOCs, D-limonene and $\beta$-ocimene, were significantly increased in all infested fruit, regardless of the fruit species. The response of the female adult $A$. melinus to olfactory cues associated with $A$. aurantii infested fruit was evaluated using a Y-tube olfactometer. In two-choice behavioural assays, A. melinus females preferred infested citrus cues over non-infested fruit. Females showed positive chemotaxis toward these VOCs in all tested combinations involving two dosages of synthetic compounds, D-limonene and $\beta$-ocimene, except for $\mathrm{D}$-limonene at a dosage of $10 \mu \mathrm{L} / \mathrm{mL}$. The application of these VOCs may help to enhance the effectiveness of bio-control programs and parasitoid mass-rearing techniques.
\end{abstract}

Keywords: California red scale; citrus fruits; volatile organic compounds; herbivore-induced; parasitoid; SPME-GC-MS

\section{Introduction}

The citrus industry is considered one of the largest fresh fruit industries in Australia, as well as the largest fresh fruit exporter, with an annual average export volume of 170,000 tonnes and a value of AUS\$190 million [1]. Aonidiella aurantii (Maskell) (Hemiptera: Diaspididae), is a major insect pest of citrus crops, causing significant production losses [2]. A. aurantii prefers to attack citrus, and it is one of the most important citrus pests worldwide [3]. A. aurantii attacks all citrus species, but there are varying levels of susceptibility, so the order of vulnerability in descending is lemon trees (Citrus limon (L.) Osbeck), grapefruit (C. xparadisi Macf.), orange (C. sinensis (L.) Osbeck) and two different species of 
mandarin (C. reticulata Blanco and C. unshiu Markovitch) [4]. California red scale A. aurantii attacks all aerial parts of the citrus tree including fruits, leaves and branches and twigs [5]. However, the fruit is the preferred plant substrate for $A$. aurantii, followed by leaves, while branches and twigs are the least preferred substrate [6]. This is economically important as the presence of this scale on fruit considerably reduces their market value, causing huge economic losses [7]. Chemical control of $A$. aurantii is difficult and is frequently followed by reinfestation within a short period, resistance to different products used for its control, and the risk of eliminating natural enemies present in the field [8].

Plant VOCs can serve as semiochemicals to protect plants from insect and pathogen attack, attract beneficial animals, and as communication signals within and among plants [9]. Terpenoids and other VOCs emitted from plants in response to insect attack allow parasitoids and predators to distinguish between infested and non-infested plants and thus aid in locating hosts or prey [10]. In addition, the herbivore-induced plant volatiles (HIPVs) vary quantitatively and qualitatively related to various biotic and abiotic factors (e.g., number of infesting pests, period and duration of infestation and previous infestation) and the VOCs are specific to each plant-pest association [11]. It is well-known that insect feeding activity leads to biochemical changes in plants. Plants respond to the presence of pests by activating their defence system [12], but they can also trigger indirect defences, such as the emission of HIPVs [13]. The role of VOCs on host location by natural enemies has been widely investigated [14,15]. Many parasitoids of phytophagous insects orient to VOCs, using them as VOCs to guide their search for hosts $[11,13]$ and differential emissions have been reported for $A$. aurantii-infested and non-infested fruits [16].

The aphelinid A. melinus is a primary ectoparasitoid of armoured scale insects. It is the most commonly used biocontrol agent for California red scale A. aurantii across the world, through augmentative releases [17,18]. A. melinus females rely on stimuli to successfully locate their host. Aphytis use learned volatile cues from host plants as long-range attractants to potential habitats of their hosts $[19,20]$. Previous work with A. melinus and California red scale showed that wasps were attracted to the odours of scale-infested lemon fruit [21].

In this study, we investigated the olfactory cues used by A. melinus females to locate their host microhabitat. We hypothesise that the VOCs from A. aurantii infested citrus fruit may play a pivotal role in affecting $A$. melinus host location. Three different citrus fruit, lemon fruit, orange fruit and mandarin fruit, were tested to determine parasitoid attractiveness and VOC emissions. First, the VOCs emitted from non-infested and infested citrus fruits were extracted with SPME fibre and analysed by gas chromatography-mass spectrometry to determine whether that VOCs are attributable to herbivores' activity and determine possible VOCs. Subsequently, we evaluated female preferences for infested or non-infested fruit in olfactometer bioassays. Finally, to understand the magnitude of volatile attractiveness, the innate attractiveness of VOCs to A. melinus females in varying concentrations was tested in the laboratory.

\section{Materials and Methods}

\subsection{Insect Colonies}

Parasitoid pupae of $A$. melinus, purchased from Biological Services Commercial Insectary (Adelaide, Australia), were maintained under laboratory conditions until adult emergence. Adults of $A$. melinus were held in plastic cages $(30 \times 30 \times 30 \mathrm{~cm})$ covered with a fine mesh cloth. The wasp colony was reared on A. aurantii; on butternut squash (Cucurbita moschata Duchesne ex Lamarck) $\left(26{ }^{\circ} \mathrm{C}, 40-60 \%\right.$ relative humidity and L16: D8 h photoperiod) during their entire life. The original A. aurantii colony was established in 2016 from infested citrus fruit harvested in Western Australia $\left(32.30^{\circ} \mathrm{S}, 116.01^{\circ}\right.$ E; $69 \mathrm{~m} \mathrm{AMSL}$ ). Fresh squash infested with scales (>1500 per squash) were placed in a cage with $A$. melinus adults which were released twice a week to maintain the A. melinus colony. 


\subsection{Plant Material}

Three different citrus species (lemon, orange and mandarin) were used for behavioural assay and GC-MS analysis. Citrus fruit was collected from 25-year-old trees (spaced $4.5 \times 5 \mathrm{~m}$ apart) on 15 September 2016, from Murdoch University citrus orchard located in Western Australia, same location as mentioned above. Non-infested or infested fruit from each citrus species was collected manually, stored in glass jars $(10 \mathrm{~cm}$ diameter, $20 \mathrm{~cm}$ high) and transferred to laboratory within $1 \mathrm{~h}$. The infested fruit samples were selected which had the most second and early third instar nymphs. Non-infested fruit samples were chosen to be free of any naturally physical damages as much as possible. Prior to test, the fruit were stored in the laboratory at $25 \pm 2{ }^{\circ} \mathrm{C}$ and $45-55 \% \mathrm{RH}$ for $5-7$ days. The tested fruit samples were uniformed in weight, each sample consisting of one piece of fruit weighing about $150 \mathrm{~g}$. The infested citrus fruit were selected with 300-400 s and early third instars of A. aurantii.

\subsection{Extraction of VOCs and GC-MS Analysis}

Random pieces of citrus fruit, either non-infested or infested, were placed individually into a $500 \mathrm{~mL}$ glass jar and sealed to equilibrate gases for 8,16 and $20 \mathrm{~h}$ for mandarin, orange and lemon, respectively. The differences in the equilibration time for extracting VOCs for each fruit could be attributed to species characteristics and many other factors such as growing area, weather conditions and non-homogeneity of the fruit ripening stage. After this, VOCs were extracted by inserting and exposing a solid-phase microextraction (SPME) fibre with 50/30 $\mu \mathrm{m}$ Carboxen/DVB/PDMS $(2 \mathrm{~cm})$ (Sigma-Aldrich, Bellefonte, PA, USA) to the headspace of the glass jar over the fruit samples at room temperature at $25 \pm 2{ }^{\circ} \mathrm{C}$ and $45-55 \% \mathrm{RH}$ for $2 \mathrm{~h}$. The fibre was then withdrawn into the needle and transferred to the injection port of the GC-MS system as described by [22]. The desorption time of the SPME fibre at GC-MS injector was $10 \mathrm{~min}$ [16]. Six replicates were conducted for each treatment. The VOCs were analysed by GC-MS using an Agilent 7820A GC (Mulgrave, Victoria, Australia), equipped with a DB-35ms $(30 \mathrm{~m} \times 0.25 \mathrm{~mm} \times 0.25 \mu \mathrm{m})$ fused-silica capillary column (Agilent Technologies, Santa Clara, CA, USA), with a mass spectrometer detector 5977E (Agilent Technologies, USA) under splitless mode. The carrier gas was $99.99 \%$ helium supplied by BOC (Sydney, Australia). The operation conditions of GC-MS were $250{ }^{\circ} \mathrm{C}$ injector temperature; the oven temperature was initially programmed at $60^{\circ} \mathrm{C}$ and increased to $270{ }^{\circ} \mathrm{C}$ (by $5^{\circ} \mathrm{C} / \mathrm{min}$ ); the column flow rate and splitless were $20 \mathrm{~mL} / \mathrm{min}$ at $1.5 \mathrm{~min}$ and 1:1; the total GC-MS run time was $45.4 \mathrm{~min}$.

Compound peaks were deconvoluted by AMDIS version 2.72 and identified by searching the NIST 2014 MS database (US National Institute of Standards and Technology, Gaithersburg, MD, USA) with retention index confirmation. The experiment was repeated twice.

\subsection{Y-Tube Olfactometer Behavioral Experiments}

The olfactory response of A. melinus to host-associated cues was tested using a glass Y-tube olfactometer purchased from Volatile Collection Systems Co LLC (Gainesville, FL, USA). The Y-tube olfactometer design was similar to that described in [19] with slight modifications for the purpose of our research. Briefly, the Y-tube olfactometer consisted of a central tube $(2.5 \mathrm{~cm}$ diameter, $15 \mathrm{~cm}$ long) and two lateral arms ( $2.5 \mathrm{~cm}$ diameter, $11 \mathrm{~cm}$ arm's length) with ground glass fittings through which humidified air passed $(0.5 \mathrm{~mL} / \mathrm{sec}$ through each arm, controlled by up-stream flow meters). Each arm was connected to an extended glass tube $(2 \mathrm{~cm}$ diameter, $6 \mathrm{~cm}$ long). The extended glass tube with the mesh barrier prevented the insects from escaping. The air was filtered with activated carbon traps, then passed through a chamber into each fruit, then VOCs and insects could be introduced. The air passed through the olfactometer and then the system was left to stabilise for $15 \mathrm{~min}$ prior to use.

Olfactometer studies were carried out at $25 \pm 1{ }^{\circ} \mathrm{C}(45-55 \% \mathrm{RH})$ in a room illuminated with overhead daylight fluorescent tubes. A light was placed over the Y-tube olfactometer, and the surrounding area (around and below) was shrouded with white paper to block out any visual cues. $A$. melinus is an ectoparasitoid, so pupae could be isolated from host and host plant material without 
disrupting their development. From adult emergence until their use for bioassays, parasitoids were held in tubes $(1 \mathrm{~cm}$ diameter, $4 \mathrm{~cm}$ length) and droplets of honey were provided throughout their lives. All wasps used for the bioassays were naive females without any previous contact with infested or non-infested host fruit. After placing parasitoids in the conditioning vial for a day, wasps were removed and placed in an empty container. On the day of bioassay, female wasps were isolated and held individually in glass vials with a drop of honey until tested. A total of 40 replicates (individual $A$. melinus) were conducted for each of the three citrus fruit species, and the four tested dosages of the synthetic VOCs. For each bioassay, a single female wasp was introduced into the central arm tube of the olfactometer. Once the wasp had reached the point where the arm divides (i.e., when the wasp reached a position to make a choice), a timer was started. If the parasitoid remained stationary for two minutes, it was considered as unresponsive. It was then excluded from the study and substituted with another one.

The olfactometer was reversed after half of the wasps in each replicate had been tested. After all ten parasitoids were assayed, the odour sources were removed, and the apparatus was cleaned with water and acetone, then dried and heated in an oven at $80^{\circ} \mathrm{C}$ for at least half an hour between replicates. Overnight between treatments, new sources were introduced into the aeration chambers, and a further replicate of ten parasitoids was tested. For bioassays involving fruit, fresh and ripe fruit samples were tested to reduce the variation in volatile emissions between replicates.

To understand whether infested citrus fruit is attractive to A. melinus, at the first stage, mated females were allowed to choose between non-infested or infested fruit samples for each citrus species. A wasp was considered to have chosen a cue when it remained in the same chamber for at least $20 \mathrm{~s}$, actively searching for a host. The bioassay replicate was considered complete when the wasp left the chamber. However, if wasps are unresponsive after two minutes in the system, they were eliminated from the study.

For assessment of the attraction of synthetic VOCs, two different concentrations (10 and $20 \mu \mathrm{L} / \mathrm{mL}$ ) of D-limonene and $\beta$-ocimene (D-limonene purity 97\%, 98\% EE (GLC) Sigma-Aldrich, and $\beta$-ocimene purity $\geq 90 \%$ Toronto Research Chemicals, North York, ON, Canada) were dissolved in hexane. In each trial, $5 \mu \mathrm{L}$ of solution was applied onto a filter paper $(1.5 \mathrm{~cm} \times 1.5 \mathrm{~cm}$ Whatman no. 1) and placed in an Erlenmeyer flask ( $250 \mathrm{~mL})$ stoppered with a sealed adaptor. After solvent evaporation $(20 \mathrm{sec})$, Erlenmeyer flask was connected to an arm of the Y-tube, and another arm received filter paper treated with $5 \mu \mathrm{L}$ of pure hexane as a solvent control. Forty mated females were tested for each treatment.

For non-infested and infested citrus fruit bioassays, the female's first choice, and search duration (time spent actively searching inside the arm) were recorded. For the bioassay of synthetic VOCs, only the female's first choice was recorded. The activity recordings of parasitoids were used to assess the overall activity and the preference for each choice. The activity was measured by summing the number of entries into both arms by each wasp.

\subsection{Statistical Analysis}

To compare VOCs emissions between infested and non-infested fruit, the variance between peak areas was analysed for each compound and chemical class. Differences in volatile emissions between non-infested and infested fruit were analysed using non-parametric Mann-Whitney U test. Principal Component Analysis (PCA) was achieved on normalised values of each VOC to derive different variables (principal components) that summarise the original data. PCA analysis was performed using Metaboanalyst 3.0 (a comprehensive online tool suite for metabolomics data analysis). A likelihood chi-square test using Yates correction (with $p=0.05$ ) for each choice-test was used to compare the proportion of parasitoids choosing a given cue. Time spent in the non-infested plant area and the infested plant area was compared using ANOVA, followed by Tukey's post hoc tests. (SPSS version 24.0, SPSS, Inc., Chicago, IL, USA). 


\section{Results}

\subsection{Identification of $V O C s$}

The data from GC-MS analysis showed that more than 34 different volatile compounds were separated and identified from the infested and non-infested citrus fruit and differential associated emissions attributed to herbivore activity were found for all fruit species (Table 1). The two naturally presented compounds in non-infested lemon, orange and mandarin, D-limonene and $\beta$-ocimene were significantly increased in the infested fruit (Table 1 ). However, $n$-hexadecanoic acid was exclusively produced by infested lemon fruit, and 5,4-di-epi-aristolochene was decreased after infestation, while 3,7-dimethyl-(E)-2,6-octadienal and $\alpha$-bulnesene were only present in non-infested lemon and were not detected in infested lemon. There were no significant differences between the non-infested and infested mandarin fruits, but the compounds of $\gamma$-terpinene, alloocimene and alloaromadendrene were significantly increased in infested mandarins (Table 1). For orange, compounds were changed only in infested fruit, e.g., three more compounds, alloaromadendrene, 4,8-dimethyl-(3E)-1,3,7-nonatriene, and hexyl caproate were increased, and five compounds, acetic acid hexyl ester, alloocimene, $\alpha$-tyerpineol, nerolidol and (3E,7E)-4,8,12-trimethyltrideca-1,3,7,11-tetraene were exclusively present in infested fruit (Table 1).

The PCA showed that the volatile compound profiles varied with infestation and citrus fruit species (Figure 1). D-Limonene and $\beta$-ocimene were the major VOCs released from all tested fruits. D-Limonene emitted $26.42 \%, 35.92 \%$ and $8.50 \%$ and $\beta$-ocimene emitted $32.83 \%, 31.51 \%$ and $17.46 \%$ of total volatile emissions from lemon, mandarin and orange fruit, respectively. Moreover, there were some major VOCs released from infested orange fruit such as alloaromadendrene, which accounted for $24.79 \%$ of total volatile emissions, and $19.65 \%$ and $23.48 \%$ of eudesma-4(14),7(11)-diene from lemon and orange fruit, respectively.

\subsection{Behavioural Tests}

The results of the Y-tube olfactory bioassays are presented in Figure 2. When olfactory cues were provided, A. melinus mated females showed significant preferences for lemon fruit infested with A. aurantti over non-infested ones, but no such preference was observed when compared between non-infested and infested oranges or mandarins. (lemon: $\chi^{2}=4.900, \mathrm{df}=1, p=0.027$; orange: $\chi^{2}$ $=2.500, \mathrm{df}=1, p=0.114$; mandarin: $\chi^{2}=1.600, \mathrm{df}=1, p=0.206$ ). There was no significant time differences of $A$. melinus to choose the chamber connected to $A$. aurantti infested citrus fruit. Indeed, $A$. melinus females slightly preferred and taken the initiative to the chambers containing infested fruit rather than health fruit (lemon: $\chi^{2}=26.000, \mathrm{df}=21, p=0.206$; orange: $\chi^{2}=28.000$, $\mathrm{df}=21, p=0.140$; mandarin: $\chi^{2}=26.333, \mathrm{df}=21, p=0.194$ ) (Table 2).

Mated A. melinus females, with no previous oviposition experience, were significantly attracted to the synthetic VOCs in all tests, with the exception of D-limonene at tested dosage $10 \mu \mathrm{L} / \mathrm{mL}\left(\chi^{2}=2500\right.$; $\mathrm{df}=1 ; p=0.114)$. However, mated $A$. melinus females preferred the reward of associated VOC more than hexane control in the case of D-limonene at the tested dosage of $20 \mu \mathrm{L} / \mathrm{mL}\left(\chi^{2}=7.410 ; \mathrm{df}=1 ; p=\right.$ $0.006), \beta$-ocimene at the tested dosage $10 \mu \mathrm{L} / \mathrm{mL}\left(\chi^{2}=4.900, \mathrm{df}=1, p=0.027\right)$ and $\beta$-ocimene at the tested dosage $20 \mu \mathrm{L} / \mathrm{mL}\left(\chi^{2}=12.100 ; \mathrm{df}=1 ; p=0.001\right)$ (Figure 3). 
Table 1. Quantities of major volatile compounds released by non-infested and Aonidiella aurantti -infested citrus fruits through headspace sampling by SPME. (GC response-Peak Areas \pm SE) $\times 10^{6}$.

\begin{tabular}{|c|c|c|c|c|c|c|c|c|}
\hline \multirow{2}{*}{ Feature ID } & \multirow{2}{*}{ NIST RI } & \multirow{2}{*}{ Chemical Compounds } & \multicolumn{2}{|c|}{ Lemon } & \multicolumn{2}{|c|}{ Mandarin } & \multicolumn{2}{|c|}{ Orange } \\
\hline & & & Non-Infested & Infested & Non-Infested & Infested & Non-Infested & Infested \\
\hline $4.464-151.1$ & 1302 * & Methoxyphenyl oxime & $4.235 \pm 1.382$ & $4.749 \pm 0.370$ & $5.568 \pm 1.504$ & $4.512 \pm 1.337$ & $12.081 \pm 2.677$ & $9.811 \pm 0.433$ \\
\hline $4.924-136.1$ & 966 & $\beta$-Thujene & n.d & n.d & $0.731 \pm 0.050$ & $2.686 \pm 1.127$ & n.d & n.d \\
\hline $5.921-136.1$ & 979 & $\beta$-Pinene & $4.464 \pm 0.064$ & $5.269 \pm 2.531$ & n.d & n.d & n.d & n.d \\
\hline $6.171-136.1$ & 991 & $\beta$-Myrcene & $3.359 \pm 2.009$ & $6.115 \pm 2.429$ & $1.211 \pm 0.405$ & $6.752 \pm 3.215$ & $0.984 \pm 0.571$ & $1.636 \pm 0.918$ \\
\hline $6.594-144.1$ & 1011 & 3-Carene & n.d & n.d & n.d & n.d & n.d & $2.754 \pm 0.4046^{*}$ \\
\hline $7.043-136.1$ & 1018 & D-Limonene & $30.852 \pm 17.394$ & $136.594 \pm 18.874^{*}$ & $31.585 \pm 6.825$ & $137.129 \pm 30.916 *$ & $24.716 \pm 1.878$ & $40.918 \pm 2.773 *$ \\
\hline $7.429-136.1$ & 1037 & $\beta$-Ocimene & $67.916 \pm 6.775$ & $169.708 \pm 13.934$ * & $45.039 \pm 18.482$ & $120.268 \pm 10.677$ * & $20.812 \pm 3.123$ & $83.942 \pm 15.674$ * \\
\hline $7.625-136.1$ & 1047 & $\gamma$-Terpinene & $3.686 \pm 2.522$ & $12.214 \pm 7.216$ & $7.117 \pm 2.606$ & $41.078 \pm 11.193 *$ & $0.573 \pm 0.498$ & $1.633 \pm 0.929$ \\
\hline $8.258-136.1$ & 1088 & Terpinolene & $2.449 \pm 1.443$ & $1.988 \pm 1.018$ & $1.431 \pm 0.251$ & $5.572 \pm 2.170$ & n.d & n.d \\
\hline $8.808-150.1$ & 1116 & (3E)-4,8-Dimethyl-1,3,7-nonatriene & $35.130 \pm 15.029$ & $18.611 \pm 1.789$ & $17.214 \pm 7.774$ & $31.584 \pm 16.498$ & $3.774 \pm 1.832$ & $32.767 \pm 10.184 *$ \\
\hline $9.092-134.1$ & 1131 & Cosmene & $4.025 \pm 0.683$ & $6.200 \pm 0.870$ & $0.635 \pm 0.319$ & $1.238 \pm 0.622$ & $1.561 \pm 0.586$ & $3.577 \pm 1.367$ \\
\hline $9.338-136.1$ & 1144 & Alloocimene & $3.653 \pm 2.236$ & $5.718 \pm 2.126$ & $1.108 \pm 0.198$ & $6.906 \pm 0.021 *$ & n.d & $2.409 \pm 0.641^{*}$ \\
\hline $9.867-128.2$ & 1177 & trans-Isopulegone & n.d & n.d & $0.191 \pm 0.191$ & $0.218 \pm 0.218$ & n.d & n.d \\
\hline $10.086-154.1$ & 1182 & 4-Terpineol & n.d & n.d & $0.284 \pm 0.146$ & $0.896 \pm 0.658$ & n.d & n.d \\
\hline 10.309-154.1 & 1189 & $\alpha$-Terpineol & $1.081 \pm 0.567$ & $1.815 \pm 1.334$ & $0.525 \pm 0.264$ & $2.975 \pm 2.476$ & n.d & $3.004 \pm 1.176^{*}$ \\
\hline $10.488-170.2$ & 1200 & Dodecane & n.d & n.d & $0.785 \pm 0.119$ & $1.126 \pm 0.195$ & n.d & n.d \\
\hline $10.614-156.1$ & 1206 & Decanal & n.d & n.d & $1.272 \pm 0.642$ & $1.312 \pm 0.667$ & $1.416 \pm 0.302$ & $1.438 \pm 0.209$ \\
\hline $11.943-152.1$ & 1270 & 3,7-Dimethyl-2,6-octadienal & $0.753 \pm 0.386$ & n.d & n.d & n.d & n.d & n.d \\
\hline $12.478-212.2$ & 1275 & 2,6,11-Trimethyldodecane & $1.369 \pm 0.819$ & $0.745 \pm 0.373$ & $1.196 \pm 0.051$ & $1.648 \pm 0.335$ & $1.371 \pm 0.108$ & $1.766 \pm 0.213$ \\
\hline $14.111-200.3$ & 1384 & Hexyl caproate & n.d & n.d & n.d & n.d & $4.375 \pm 1.713$ & $18.305 \pm 6.018^{*}$ \\
\hline $14.206-204.2$ & 1398 & $\beta$-Elemene & $7.433 \pm 2.337$ & $5.899 \pm 0.894$ & n.d & n.d & $10.546 \pm 4.774$ & $20.594 \pm 5.217$ \\
\hline $14.922-204.2$ & 1461 & Alloaromadendrene & $17.374 \pm 5.366$ & $13.587 \pm 0.729$ & $3.454 \pm 0.358$ & $7.713 \pm 0.894^{*}$ & $39.032 \pm 7.499$ & $119.291 \pm 13.459 *$ \\
\hline $15.236-204.2$ & 1490 & $\alpha$-Bulnesene & $1.309 \pm 0.805$ & n.d & n.d & n.d & n.d & n.d \\
\hline $15.384-204.2$ & 1440 & Aromandendrene & n.d & n.d & n.d & n.d & $4.920 \pm 1.749$ & $9.635 \pm 2.296$ \\
\hline $15.784-204.2$ & 1469 & 5,4-di-epi-Aristolochene & $2.391 \pm 0.345^{*}$ & $1.435 \pm 0.103$ & n.d & n.d & $3.789 \pm 1.474$ & $7.687 \pm 0.861$ \\
\hline $15.941-204.2$ & 1527 & Panasinsene & $16.519 \pm 6.276$ & $10.936 \pm 2.061$ & n.d & n.d & $11.113 \pm 4.743$ & $20.255 \pm 2.813$ \\
\hline $16.283-204.2$ & 1544 & Eudesma-4(14),7(11)-diene & $51.037 \pm 45.977$ & $101.571 \pm 76.637$ & n.d & n.d & $100.882 \pm 27.236$ & $113.043 \pm 38.383$ \\
\hline $17.039-204.2$ & 1556 & Guaia-3,9-diene & $1.705 \pm 0.296$ & $2.091 \pm 0.595$ & n.d & n.d & n.d & n.d \\
\hline $17.323-222.2$ & 1564 & Nerolidol & $3.129 \pm 2.278$ & $2.652 \pm 1.351$ & n.d & n.d & n.d & $1.247 \pm 0.644$ \\
\hline $17.532-218.2$ & 1581 & $(3 E, 7 E)-4,8,12$-Trimethyltrideca-1,3,7,11- tetraene & n.d & n.d & $1.941 \pm 0.766$ & $2.587 \pm 1.083$ & n.d & $1.582 \pm 0.821$ * \\
\hline $17.849-220.2$ & 1586 & trans $-(\mathrm{Z})-\alpha$-Bisabolene epoxide & $1.355 \pm 0.319$ & $1.322 \pm 0.359$ & $0.142 \pm 0.1416$ & $0.155 \pm 0.155$ & n.d & n.d \\
\hline $18.945-222.2$ & 1660 & Neointermedeol & $3.218 \pm 0.332$ & $4.672 \pm 0.699$ & $0.348 \pm 0.182$ & $0.566 \pm 0.288$ & $1.275 \pm 0.332$ & $2.305 \pm .389$ \\
\hline $23.368-256.2$ & 1968 & $\mathrm{n}$-Hexadecanoic acid & n.d & $0.920 \pm 0.920$ & $3.098 \pm 1.076$ & $3.336 \pm 0.928$ & n.d & n.d \\
\hline $44.331-722.6$ & 4932 * & Trimyristin & $2.843 \pm 2.201$ & $2.088 \pm 0.529$ & $1.343 \pm 0.458$ & $1.416 \pm 0.266$ & n.d & n.d \\
\hline
\end{tabular}

Asterisks indicate significant differences between uninfected and infested fruit at $p<0.05$; Feature ID includes retention time (min) and $m / z$ ratio $z$; RI retention index obtained from the NIST database; * Estimated non-polar retention index ( $n$-alkane NIST scale); SE = standard error; n.d = not detected. Each value represents the peak area (mean \pm SE) of $n=6$ analyses. 

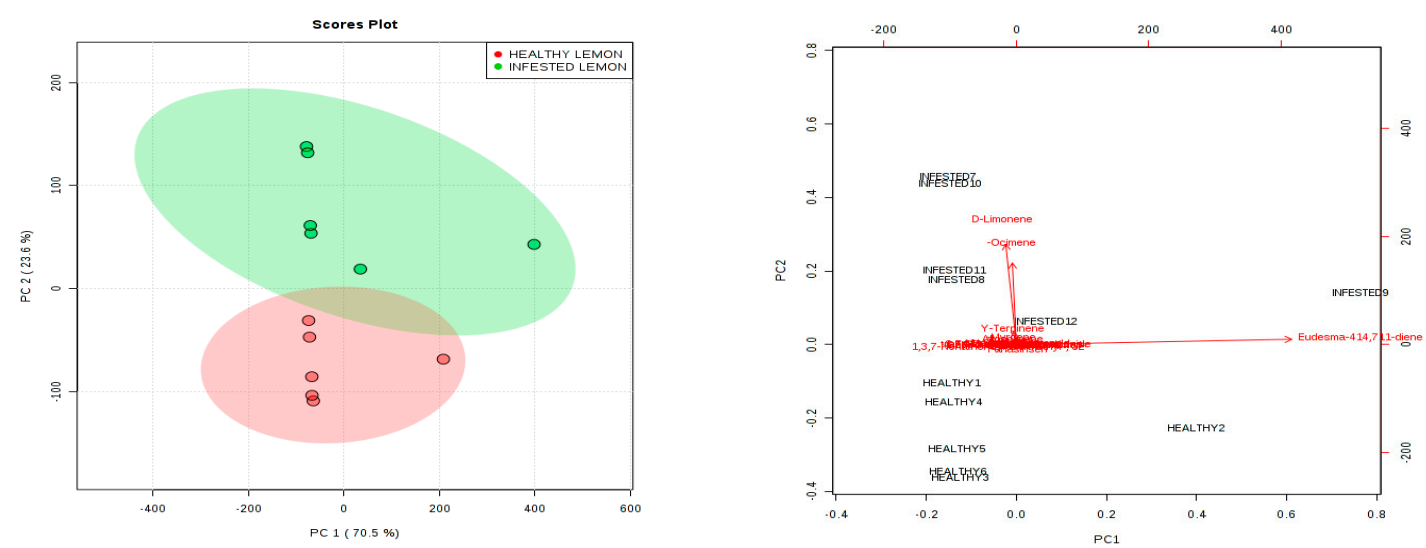

(a)
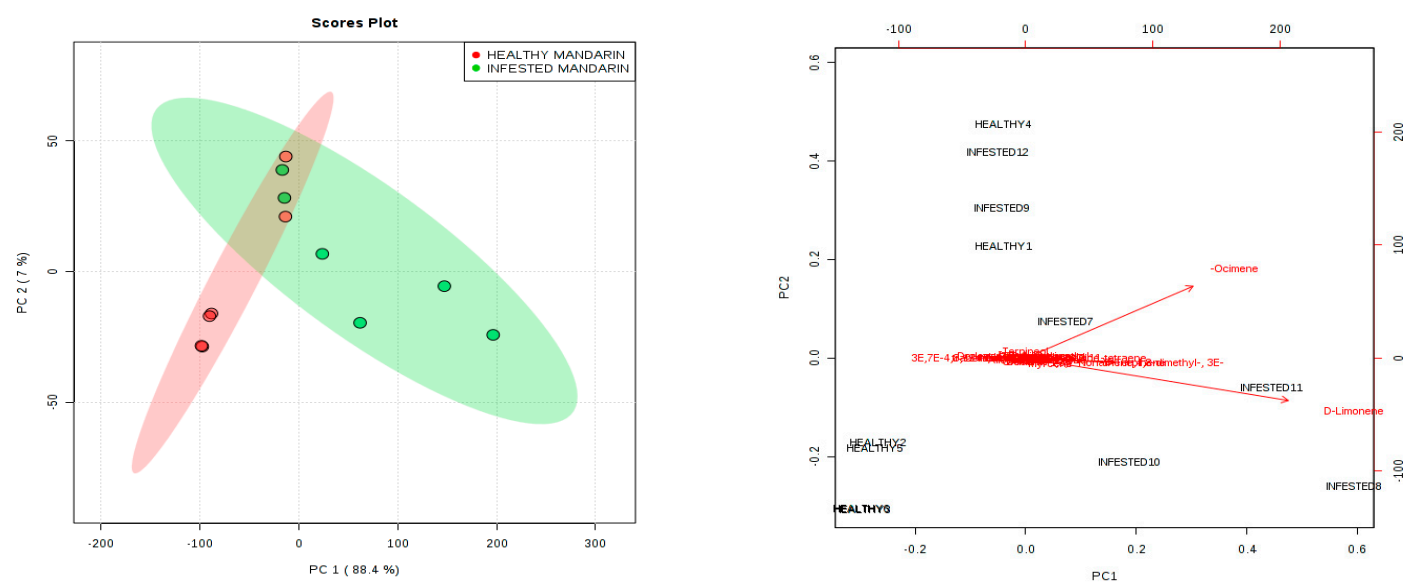

(b)
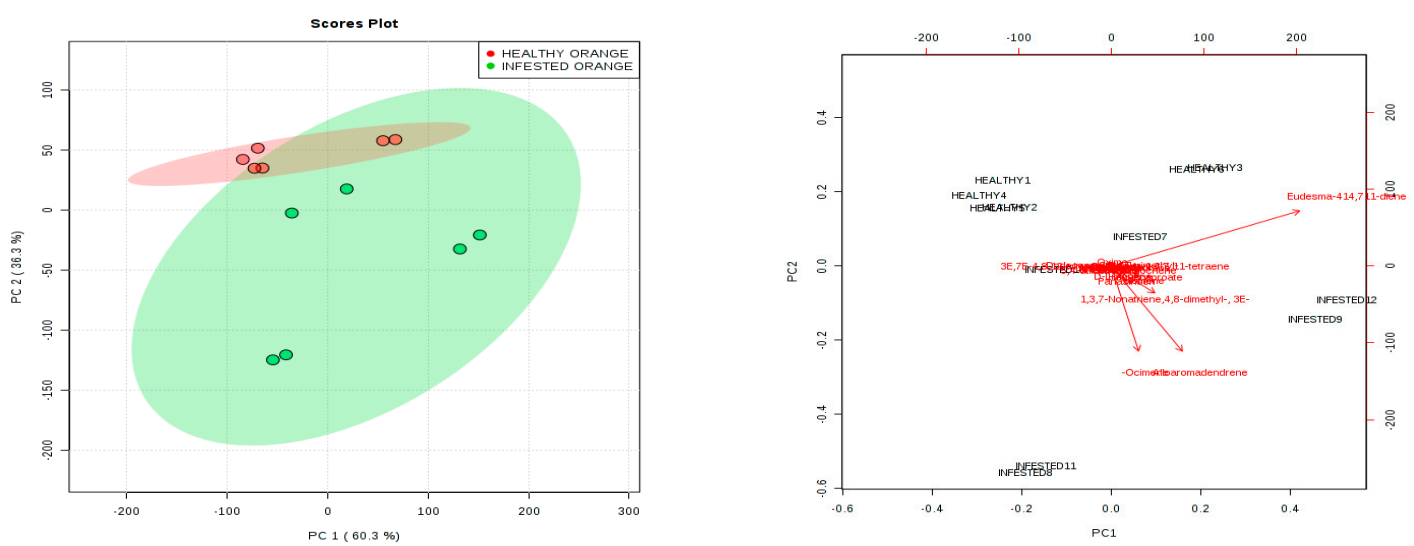

(c)

Figure 1. Principal Component Analysis (PCA) of volatile profiles from infested and non-infested fruit of three different citrus species. PCA scores plot and biplot of lemon (a), mandarin (b) and orange fruit (c), showing volatile correlations with the first and second principal component; PCA score plot, highlighting cluster of VOCs attributable to species or infestation status; PCA biplot highlighting changes in chemicals attribute to species or infestation status. 


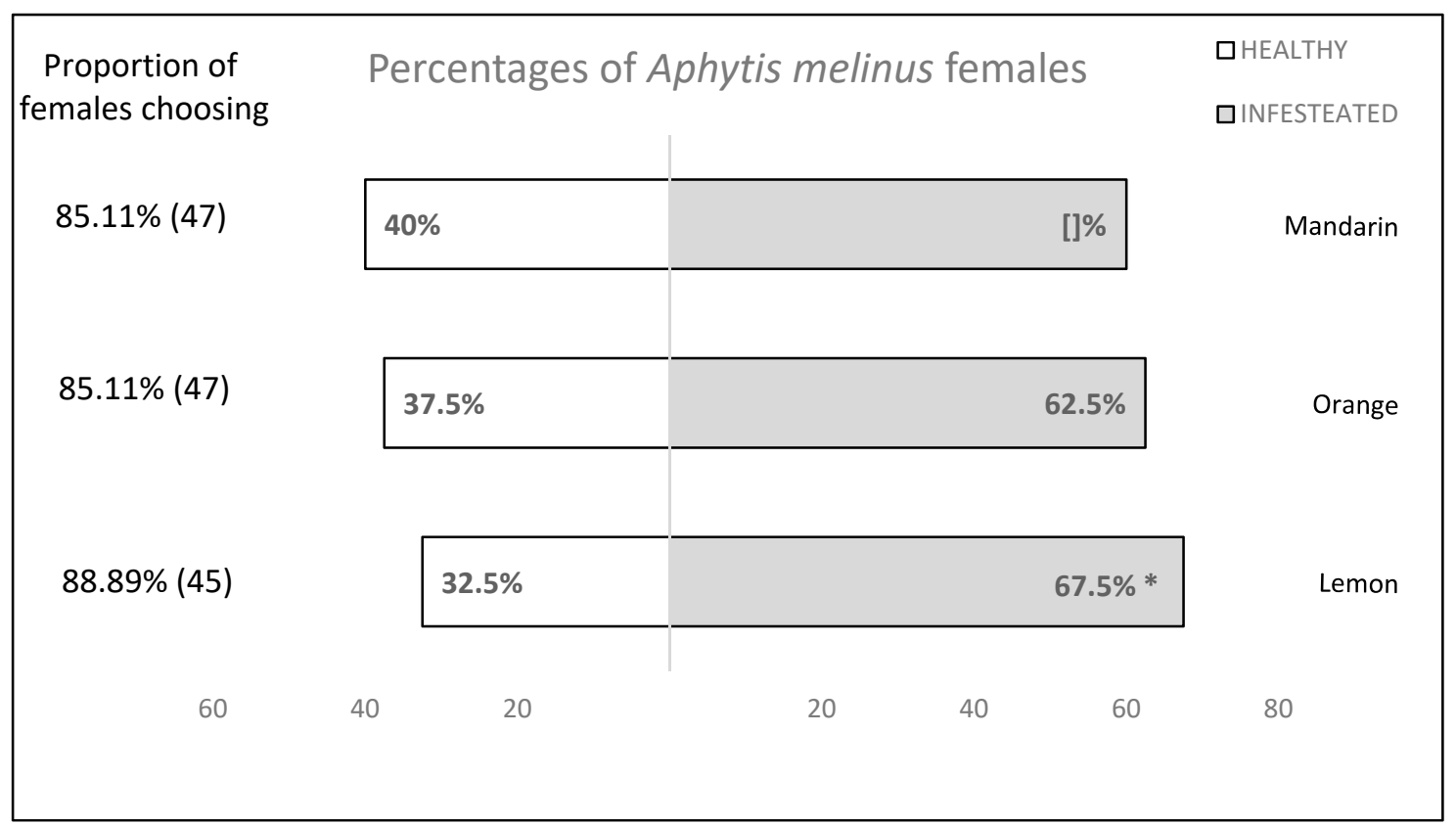

Figure 2. Attractiveness of Aonidiella aurantii-infested citrus fruit towards Aphytis melinus mated females. Two choice bioassays were conducted in a still air arena with citrus fruit, infested or not by California red scale, providing olfactory cues. Forty wasps were tested in each bioassay. For each test, asterisks indicate significant differences in the number of wasps choosing different cue ( $\chi^{2}$ test with Yates correction, $p<0.05$ ). To the left of the bars is the proportion of females that made a choice for one of the two odours, as well as the total number of females that were tested.

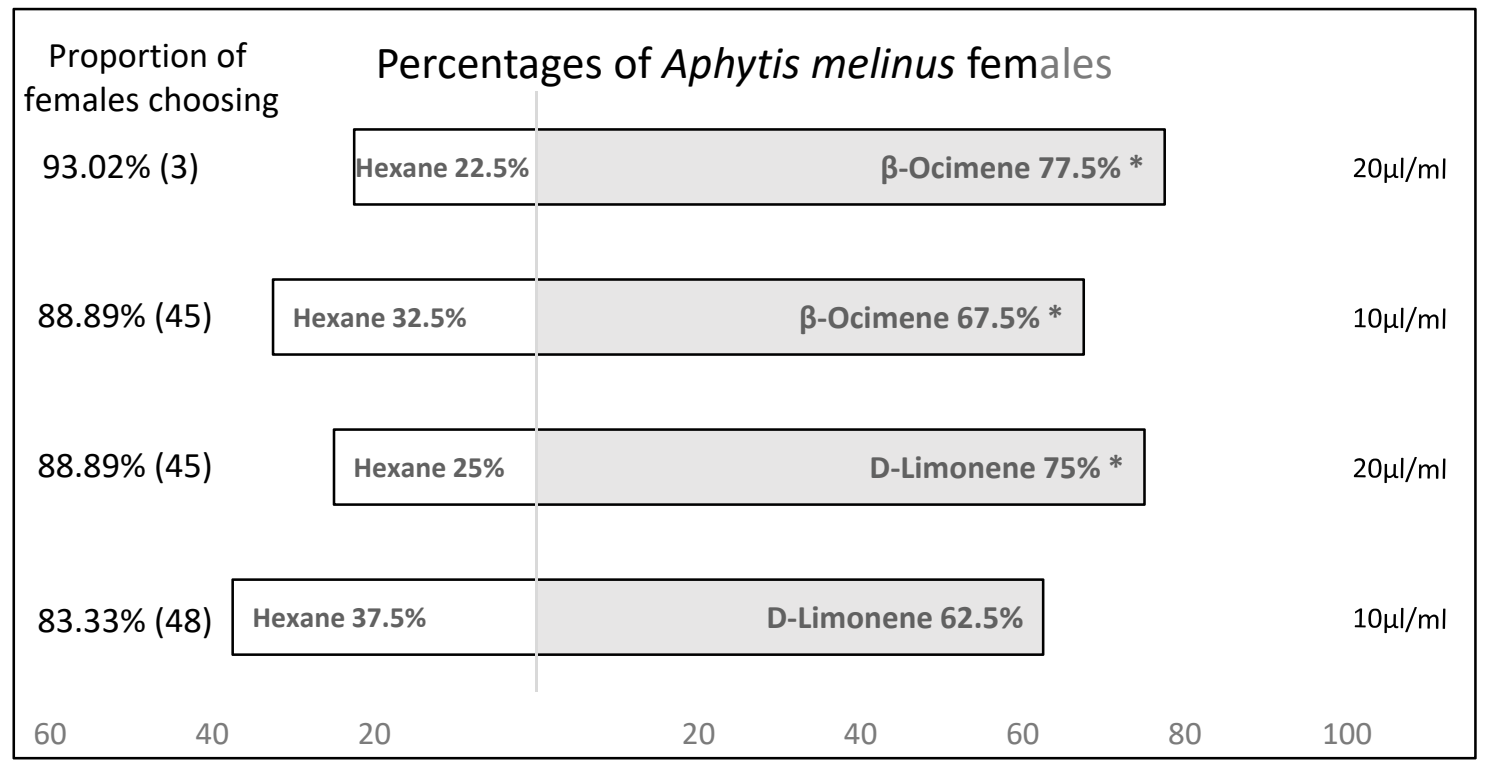

Figure 3. Attraction of female Aphytis melinus to VOCs differentially emitted by A. aurantti-infested citrus fruits. Choice bioassays were conducted in a Y-tube olfactometer presenting one of the two dosage levels (10 and $20 \mu \mathrm{L} / \mathrm{mL}$ ) of citrus fruits VOCs vs. hexane. Asterisks indicate significant differences between numbers of VOC and control choices ( $\chi^{2}$ test with Yates' correction, $\left.p<0.05\right)$. To the left of the bars is the proportion of females that made a choice for one of the two odours, as well as the total number of females that were tested. 
Table 2. Choice time spent by Aphytis melinus females during searching behaviour on non-infested and Aonidiella aurantii -infested citrus fruits in Y-tube Olfactometry.

\begin{tabular}{cccccccc}
\hline \multirow{2}{*}{ Species } & \multicolumn{2}{c}{ Infested Citrus Fruit } & \multicolumn{2}{c}{ Non-Infested Citrus Fruit } & & F \\
\cline { 2 - 5 } & $\begin{array}{c}\text { Choice Time (s) } \\
\text { Mean } \pm \text { SE }\end{array}$ & Replicates & $\begin{array}{c}\text { Choice Time (s) } \\
\text { Mean } \pm \text { SE }\end{array}$ & Replicates & F & -Value \\
\hline Lemon & $148.15 \pm 13.482$ & 27 & $133.31 \pm 14.604$ & 13 & 0.558 & $0.206^{\mathrm{ns}}$ \\
Orange & $153.40 \pm 10.523$ & 25 & $119.13 \pm 12.084$ & 15 & 4.573 & $0.140^{\mathrm{ns}}$ \\
Mandarin & $139.53 \pm 12.802$ & 23 & $144.06 \pm 15.412$ & 17 & 0.051 & $0.194^{\mathrm{ns}}$ \\
\hline
\end{tabular}

ns: no significant differences in choice time spent by Aphytis melinus between uninfected and infested fruit at $p<$ 0.05; ns: not significant.

\section{Discussion}

This report investigated the capability of an aphelinid parasitoid A. melinus to respond to citrus fruit chemical cues associated with damage induced by a phytophagous pest. The results indicated that $A$. melinus was able to discriminate between citrus fruit infested with $A$. aurantii and non-infested fruit by using olfactory cues.

Among 34 VOCs extracted and identified by SPME and GC-MS techniques, only two VOCs, $\mathrm{D}$-limonene, and $\beta$-ocimene were increased in all infested three citrus species, which were already known as a constituent of the odours of citrus fruit and citrus oils $[16,20,23]$. However, since D-limonene and $\beta$-ocimene are attractive to many other parasitoid species $[19,20,24]$, these two compounds can be considered as putative VOCs as attractants of A. melinus.

PCA analysis has highlighted that VOC emissions are particular for each species and chemical. Fruits differentially emitted the VOCs after insect infestation and the VOCs change depending on the citrus species. Indeed, several plants react to herbivore damage by producing blends of metabolites that change in number or proportion [25]. The increasing in VOCs follow the infestation could be explained for all species, but we also identified some particular compounds emitted under the condition of $A$. aurantii infestation. Besides D-limonene and $\beta$-ocimene, infested mandarin fruits displayed increased emissions of another three compounds ( $\gamma$-terpinene, alloocimene and alloaromadendrene). Infested lemon fruits increased the emission of just $\mathrm{D}$-limonene and $\beta$-ocimene and produced $n$-hexadecanoic acid. When attacked by $A$. aurantii, orange fruits similar to other species increased the production of $\mathrm{D}$-limonene, $\beta$-ocimene, $(3 E)$-4,8-dimethyl-,1,3,7-nonatriene, hexyl caproate and alloaromadendrene, and exclusively produced five compounds (acetic acid, hexyl ester, alloocimene, $\alpha$-terpineol, nerolidol and (3E,7E)-4,8,12-trimethyltrideca-1,3,7,11-tetraene). Most of these compounds are known as common floral compounds, but interestingly some of them are also recognised as pheromones for several hymenopteran species [26].

Since the variance in VOCs depends mainly on the fruit species, we cannot exclude the possibility that other VOCs produced specifically by one species or increased in all species may act as an attractant toward A. melinus. Indeed, non-infested fruit also produce VOCs that are attractive to parasitoids [25], and aphelinid parasitoids, such as A. melinus could be able to perceive cues from non-infested plants to locate a host $[19,20]$. Therefore, short-range VOCs produced by the plants or as feeding larvae secretion could be useful for successful localisation [27]. Overall, since VOCs are known to act as attractive chemicals for several parasitoids $[25,28,29]$, further research is needed to assess the activity of these compounds on parasitoid behaviour. Indeed, understanding tritrophic system communications has potential implications for biological control programs [30].

Olfactory cues from host-infested fruit are known to be essential for parasitoids during foraging for hosts, food and mates in complex environments [13,31]. For A. melinus, the source of volatile cues that the wasp uses to locate the host species were determined when those hosts occurred on more than one host plant species [19]. The evidence that olfactory cues from infested fruit evoke behavioural responses from mated A. melinus females, and the presence of chemicals that were produced exclusively or in higher amounts by infested citrus fruit, supported our hypothesis that VOCs could act as short-range 
attractants and played a key role during host-seeking. Biological assays conducted in the olfactometer indicated that $A$. melinus preferentially orientated towards the source of VOCs, that is, the presence of A. aurantii on the fruit is crucial for host location.

The VOCs D-limonene and $\beta$-ocimene have been reported as bouquet constituents of several citrus species $[16,20]$. D-Limonene and $\beta$-ocimene were identified as constituents of different infested fruit species that attracted other parasitoids such as Agathis bishopi and Aphidius gifuensis [24,32]. Many experiments have shown that, in the species examined, successful source location requires the presence of an attractive odour [33].

It is clear that $A$. melinus was not attracted to the pest when fruit material was absent, suggesting the importance of plant VOCs as long-range attractants of parasitoids, this result is consistent with that host insects do not always produce good cues [34]. This study confirmed that the aphelinid parasitoid A. melinus uses common VOCs to locate prey. The volatile profile analysis provides complementary information about the composition of the volatile chemicals potentially involved in the behaviours with 34 compounds varying during infestation by $A$. aurantii. Further electrophysiology and behavioural assays are expected to provide more accurate identification of the VOCs that contribute towards attracting $A$. melinus to infested host citrus fruit. Such information may prove useful for further studies aiming at developing semiochemical strategies that could be incorporated into an integrated management approach for enhancing existing pest control techniques for California red scale.

\section{Conclusions}

The aphelinid parasitoid $A$. melinus responded to citrus fruit chemical cues associated with damage induced by California red scale. The analytical data showed that more than 34 different volatile compounds were separated and identified from the infested and non-infested citrus species fruit. Interestingly, the three-species showed two common VOCs increased as a response of $A$. aurantii infestation: D-limonene and $\beta$-ocimene.

Olfactory cues seem to have a key role in host-seeking behaviour for the three citrus species. Synthetic VOCs may be useful to improve biological control programs especially after VOCs are recognized as VOCs of a number of parasitic wasps, but still, further studies are necessary to ensure the behavioural activity of this investigated VOCs toward A. melinus parasitoids under field condition.

Author Contributions: For conceptualization, K.M., M.A., Y.R. and T.L.; methodology, K.M., M.A., Y.R., T.L., B.L. and J.N.; funding acquisition, K.M. and Y.R.; formal analysis, K.M., J.N. and B.L.; investigation, K.M.; resources, M.A., Y.R. and T.L.; data curation, K.M., B.L. and J.N.; writing-original draft preparation, K.M.; writing-review and editing, K.M., M.A., Y.R. and T.L.; visualization, K.M. and Y.R.; supervision, M.A., Y.R. and T.L.; project administration, K.M. and Y.R. All authors have read and agreed to the published version of the manuscript.

Funding: This research received no external funding.

Acknowledgments: We thank Mosul University for a scholarship and support to the first author. We thank Xin Bob Du, Murdoch University Laboratory staff, for their technical support; Bob Fawcett, farm Supervisor (Whitby Falls), for facilitating collection samples.

Conflicts of Interest: The authors declare no conflict of interest.

\section{References}

1. Murray-Darling Basin Authority. Guide to the Proposed Basin Plan; Murray-Darling Basin Authority: Canberra, Australia, 2010.

2. El-Otmani, M.; Ait-Oubahou, A.; Zacarías, L. Citrus spp.: Orange, mandarin, tangerine, clementine, grapefruit, pomelo, lemon and lime. In Postharvest Biology and Technology of Tropical and Subtropical Fruits: Açai to Citrus; Woodhead Publishing Limited: Cambridge, UK, 2011; pp. 437-516. [CrossRef]

3. Tena, A.; Garcia-Marí, F. Current situation of citrus pests and diseases in the Mediterranean basin. IOBC Bull. 2011, 62, 365-368.

4. Habib, A.; Salama, H.S.; Amin, A.H. Population of Aonidiella aurantii on citrus varieties in relation to their physical and chemical characteristics. Entomol. Exp. Appl. 1972, 15, 324-328. [CrossRef] 
5. Beardsley, J.W., Jr.; Gonzalez, R.H. The biology and ecology of armored scales. Ann. Rev. Entomol. 1975, 20, 47-73. [CrossRef] [PubMed]

6. Hare, J.D.; Yu, D.S.; Luck, R.F. Variation in life history parameters of California red scale on different citrus cultivars. Ecology 1990, 71, 1451-1460. [CrossRef]

7. Vacas, S.; Alfaro, C.; Navarro-Llopis, V.; Primo, J. Mating disruption of California red scale, Aonidiella aurantii Maskell (Homoptera: Diaspididae), using biodegradable mesoporous pheromone dispensers. Pest Manag. Sci. 2010, 66, 745-751. [CrossRef]

8. Mellado, J.J.S. Biological Control of California Red Scale, Aonidiella aurantii (Hemiptera: Diaspididae): Spatial and Temporal Distribution of Natural Enemies, Parasitism Levels and Climate Effects. Ph.D. Thesis, Polytechnic University of Valencia, Valencia, Spain, 2012. [CrossRef]

9. Baldwin, I.T. Plant volatiles. Curr. Biol. 2010, 20, R392-R397. [CrossRef]

10. Paré, P.W.; Farag, M.A. Natural enemy attraction to plant volatiles. In Encyclopedia of Entomology; Springer: Dordrecht, The Netherlands, 2004; pp. 1534-1535. [CrossRef]

11. Benelli, G.; Revadi, S.; Carpita, A.; Giunti, G.; Raspi, A.; Anfora, G.; Canale, A. Behavioral and electrophysiological responses of the parasitic wasp Psyttalia concolor (Szépligeti)(Hymenoptera: Braconidae) to Ceratitis capitata-induced fruit volatiles. Biol. Control 2013, 64, 116-124. [CrossRef]

12. Gonzalez-Aguilar, G.A.; Tiznado-Hernandez, M.E.; Zavaleta-Gatica, R.; Martınez-Téllez, M.A. Methyl jasmonate treatments reduce chilling injury and activate the defense response of guava fruits. Biochem. Biophys. Res. Commun. 2004, 313, 694-701. [CrossRef]

13. Hare, J.D. Ecological role of volatiles produced by plants in response to damage by herbivorous insects. Ann. Rev. Entomol. 2011, 56, 161-180. [CrossRef]

14. Dicke, M.; Baldwin, I.T. The evolutionary context for herbivore-induced plant volatiles: Beyond the 'cry for help'. Trends Plant Sci. 2010, 15, 167-175. [CrossRef]

15. Kaplan, I. Trophic complexity and the adaptive value of damage-induced plant volatiles. PLoS Biol. 2012, 10, e1001437. [CrossRef] [PubMed]

16. Mohammed, K.; Agarwal, M.; Mewman, J.; Ren, Y. Optimization and Validation for Determination of VOCs from Lime Fruit Citrus aurantifolia (Christm.) with and without California Red Scale Aonidiella aurantii (Maskell) Infested by Using HS-SPME-GC-FID/MS. World Acad. Sci. Eng. Technol. Int. J. Biol. Biomol. Agric. Food Biotechnol. Eng. 2017, 9, 771-775.

17. Rizqi, A.; Bouchakour, M.; Aberbach, A.; Nia, M. The use of Aphytis melinus for control of California Red Scale in Citrus growing region of Souss in Morocco. In Proceedings of the 10th International Citrus Congress, III, Agadir, Morocco, 15-20 February 2004; Volume 991.

18. Tena, A.; Urbaneja, A. Feeding behaviour of a California red scale parasitoid in citrus orchards. Acta Hortic. 2015, 1065, 1145-1148. [CrossRef]

19. Morgan, D.J.; Hare, J.D. Volatile cues used by the parasitoid, Aphytis melinus, for host location: California red scale revisited. Entomol. Exp. Appl. 1998, 88, 235-245. [CrossRef]

20. Mohammed, K.; Agarwal, M.; Du, X.B.; Newman, J.; Ren, Y. Behavioural responses of the parasitoid Aphytis melinus to volatiles organic compounds (VOCs) from Aonidiella aurantii on its host fruit Tahitian lime fruit Citrus latifolia. Biol. Control 2019, 133, 103-109. [CrossRef]

21. Sternlicht, M. Parasitic wasps attracted by the sex pheromone of their coccid host. Entomophaga 1973, 18, 339-342. [CrossRef]

22. Mohammed, K.; Agarwal, M.; Newman, J.; Ren, Y. Optimization of headspace solid-phase microextraction conditions for the identification of volatiles compounds from the whole fruit of lemon, lime, mandarin and orange. J. Biosci. Med. 2017, 5, 176-186. [CrossRef]

23. Auta, M.; Musa, U.; Tsado, D.G.; Faruq, A.A.; Isah, A.G.; Raji, S.; Nwanisobi, C. Optimization of citrus peels D-limonene extraction using solvent-free microwave green technology. Chem. Eng. Commun. 2018, 205, 789-796. [CrossRef]

24. Kang, Z.W.; Liu, F.H.; Zhang, Z.F.; Tian, H.G.; Liu, T.X. Volatile $\beta$-ocimene can regulate developmental performance of peach aphid Myzus persicae through activation of defense responses in Chinese cabbage Brassica pekinensis. Front. Plant Sci. 2018, 9, 708. [CrossRef]

25. Carrasco, M.; Montoya, P.; Cruz-Lopez, L.; Rojas, J.C. Response of the fruit fly parasitoid Diachasmimorpha longicaudata (Hymenoptera: Braconidae) to mango fruit volatiles. Environ. Entomol. 2005, 34, 576-583. [CrossRef] 
26. Pinto-Zevallos, D.M.; Hellén, H.; Hakola, H.; van Nouhuys, S.; Holopainen, J.K. Induced defences of Veronica spicata: Variability in herbivore-induced volatile organic compounds. Phytochem. Lett. 2013, 6, 653-656. [CrossRef]

27. Canale, A. Psyttalia concolor (Hymenoptera Braconidae): Role of host movement and host substrate in ovipositor-probing behaviour. Bull. Insectol. 2003, 56, 211-214.

28. Zimba, K.; Hill, M.P.; Moore, S.D.; Heshula, U. Agathis bishopi (Hymenoptera: Braconidae) as a potential tool for detecting oranges infested with Thaumatotibia leucotreta (Lepidoptera: Tortricidae). J. Insect Behav. 2015, 28, 618-633. [CrossRef]

29. Giunti, G.; Benelli, G.; Flamini, G.; Michaud, J.P.; Canale, A. Innate and learned responses of the tephritid parasitoid Psyttalia concolor (Hymenoptera: Braconidae) to olive volatiles induced by Bactrocera oleae (Diptera: Tephritidae) infestation. J. Econ. Entomol. 2016, 109, 2272-2280. [CrossRef]

30. Uefune, M.; Choh, Y.; Abe, J.; Shiojiri, K.; Sano, K.; Takabayashi, J. Application of synthetic herbivore-induced plant volatiles causes increased parasitism of herbivores in the field. J. Appl. Entomol. 2012, 136, 561-567. [CrossRef]

31. Clavijo Mccormick, A.N.D.R.E.A.; Gershenzon, J.; Unsicker, S.B. Little peaks with big effects: Establishing the role of minor plant volatiles in plant-insect interactions. Plant Cell Environ. 2014, 37, 1836-1844. [CrossRef]

32. Zimba, K.J. Using the Larval Parasitoid, Agathis Bishopi (Nixon) (Hymenoptera: Braconidae), for Early Detection of False Codling Moth, Thaumatotibia Leucotreta (Meyrick) (Lepidoptera: Tortricidae) Infested Fruit. Ph.D. Thesis, Rhodes University, Grahamstown, South Afica, 2014.

33. Cardé, R.T.; Willis, M.A. Navigational strategies used by insects to find distant, wind-borne sources of odour. J. Chem. Ecol. 2008, 34, 854-866. [CrossRef]

34. Heil, M. Indirect defence via tritrophic interactions. New Phytol. 2008, 178, 41-61. [CrossRef]

(C) 2020 by the authors. Licensee MDPI, Basel, Switzerland. This article is an open access article distributed under the terms and conditions of the Creative Commons Attribution (CC BY) license (http://creativecommons.org/licenses/by/4.0/). 